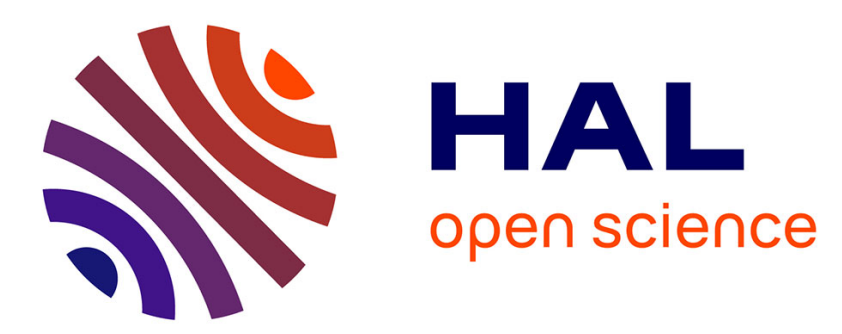

\title{
Influence of Genetic Background on Apathy-Like Behavior in Triple Transgenic AD Mice
}

Raphaelle Piquard Pardossi, I. Lauritzen, C. Bauer, G. Sacco, P. Robert, F. Checler

\section{- To cite this version:}

Raphaelle Piquard Pardossi, I. Lauritzen, C. Bauer, G. Sacco, P. Robert, et al.. Influence of Genetic Background on Apathy-Like Behavior in Triple Transgenic AD Mice. Current Alzheimer Research, 2016, 13 (8), pp.942-949. 10.2174/1567205013666160404120106 . hal-02361218

\section{HAL Id: hal-02361218 https://hal.science/hal-02361218}

Submitted on 12 Nov 2020

HAL is a multi-disciplinary open access archive for the deposit and dissemination of scientific research documents, whether they are published or not. The documents may come from teaching and research institutions in France or abroad, or from public or private research centers.
L'archive ouverte pluridisciplinaire HAL, est destinée au dépôt et à la diffusion de documents scientifiques de niveau recherche, publiés ou non, émanant des établissements d'enseignement et de recherche français ou étrangers, des laboratoires publics ou privés. 


\title{
Influence of Genetic Background on Apathy-Like Behavior in Triple Transgenic AD Mice
}

\author{
R. Pardossi-Piquard ${ }^{1, \#}$, I. Lauritzen ${ }^{1, \#}$, C. Bauer ${ }^{1}$, G. Sacco ${ }^{2,3}$, P. Robert ${ }^{2,3}$ and F. Checler ${ }^{1, *}$
}

${ }^{1}$ IPMC, UMR7275 CNRS/UNS, Laboratory of Excellence DistALZ, 660 route des Lucioles, 0660 Valbonne, France; ${ }^{2}$ EA 7276 CoBTeK Cognition Behaviour Technology, University of Nice Sophia Antipolis; ${ }^{3}$ CMRR, Memory Center, Pôle de Gérontologie, CHU, Nice, France

\begin{abstract}
Apathy is an early and common neuropsychiatric syndrome in Alzheimer's disease (AD) patients. In clinical trials, apathy is associated with decreased motor activity that can be monitored by actigraphy. The triple transgenic mouse AD model (3xTgAD) has been shown to recapitulate the biochemical lesions as well as many of the synaptic and cognitive alterations associated with AD. In the present work we found that these mice also develop an early and consistent apathy-like behavior as evidenced by a drastic decrease in spontaneous activity measured by actimetry. We recently estab-

F. Checler lished that these mice also display an intraneuronal accumulation of the $\beta$-secretase-derived $\beta$ APP fragment (C99) appearing early, in absence of A $\beta$. Interestingly, we found that the apathy-like behavior observed in 3xTgAD mice was temporally associated with C99 accumulation and synaptic alterations. Since it is well known that the genetic background can strongly influence behavior and can induce transcriptional variability in animal models, we decided to determine the influence of genetic background on the above-described alterations. We backcrossed 3xTgAD mice to C57BL/6 and found that the genetic background had no influence on either C99 accumulation or synaptic plasticity alterations, but strongly affected the apathy-like behavior.
\end{abstract}

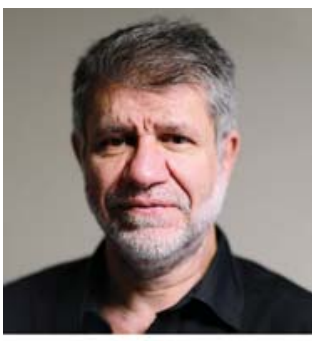

Keywords: Apathy, behavior, C99, LTP, immunohistochemistry, triple transgenic mice, genetic background.

\section{INTRODUCTION}

Genetic grounds indicate that $\beta$ APP processing is essential for the development of Alzheimer's disease pathology [1]. Thus, autosomal dominant familial forms of Alzheimer's disease are associated with mutations on gene products directly linked to either $\beta$ APP itself or to one of its main catabolizing enzyme $\gamma$-secretase $[2,3]$. All these mutations have been reported to modulate, to various extents, the nature and/or the load of secretase-mediated $\beta$ APP-derived fragments.

Numerous animal models based on overexpression of either mutated proteins [4-6] or A $\beta$ itself [7] have been designed in an attempt to obtain tools for drug screening and hypotheses validations $[8,9]$. These models have been reported to recapitulate at least some of the biochemical lesions, synaptic alterations and cognitive defects reminiscent of those observed in human AD. The triple transgenic mouse, $3 \times \operatorname{TgAD}\left(\mathrm{PS}_{\mathrm{M} 146 \mathrm{~V}}, \mathrm{APP}_{\mathrm{swe}}, \mathrm{Tau}_{\mathrm{P} 301 \mathrm{~L}}\right.$ ) is one of the first animal models presenting both amyloid- and tau-linked pathologies[10]. Besides presenting plaques and tangles, it also develops age-related synaptic dysfunction and cognitive defects related to learning and memory [11]. The development of these mice was therefore considered as a genuine step forward the design of integrated models allowing better understanding of AD pathology.

\footnotetext{
*Address correspondence to this author at the IPMC, UMR7275 CNRS/UNS, Laboratory of Excellence DistALZ, 660 route des Lucioles, 0660 Valbonne, France; Tel: (33) 4939534 60; Fax: (33) 4939534 08; E-mail: checler@ipmc.cnrs.fr

"equally contributed to this work.
}

Although it has been considered mainly as a memory disorder, $\mathrm{AD}$ is also associated with non-cognitive behavioral symptoms which are often early signs of the disease and strongly contribute to disease progression. Apathy appears to be the most common and earliest behavioral symptom in AD [12-14]. It is broadly defined by a quantitative reduction of voluntary goal-directed behavior and selfinitiated activity. Moreover, it has been shown to be associated with a decrease of motor activity that can be assessed by ambulatory actigraphy thereby providing an indirect objective evaluation of apathy [15-17]. In the present work, we decided to use actimetry to determine whether an apathy-like behavior could be detected in 3xTgAD mice. This technique allows an evaluation of spontaneous activity of mice in home-cage situations and has been useful to depict an apathy-like behavior in a murine model of chronic stress [18]. Indeed, young $3 \times \mathrm{TgAD}$ mice were found to display drastically reduced spontaneous activity in the actimeter, while they behaved normally in the rotarod performance test, indicating that the reduced activity was linked to diminished voluntary activity rather to reduced locomotor ability. Interestingly, this behavior was temporally associated with the intraneuronal accumulation of the $\beta$-secretase-derived Cterminal fragment $\mathrm{C} 99$ in the subiculum of $3 \times \mathrm{TgAD}$ mice, and occurred before $A \beta 40$ or $A \beta 42$ could be detected [19]. As reported by others, these mice also showed an early agedependent decrease in LTP that we again found to be temporally correlated with C99 accumulation. After backcrossing 3xTgAD mice into the C57B16 background, we established that the genetic background had no influence on either C99 
accumulation or synaptic plasticity alterations, but that it strongly affected the apathy-like behavior.

\section{MATERIAL AND METHOD}

\subsection{Animals}

A colony of $3 \times \mathrm{TgAD}$ (harbouring $\mathrm{PS}_{\mathrm{M} 146 \mathrm{~V}}$ knockin, $\mathrm{APP}_{\text {swe }}$, and Tau $\mathrm{P}_{\mathrm{P} 01 \mathrm{~L}}$ transgenes (10) and non-transgenic (WT) mice were generated from breeding pairs provided by Dr. LaFerla from the University of California Irvine. The mice were kept on the original 129-C57BL/6 background strain or backcrossed to $\mathrm{C} 57 \mathrm{BL} / 6$ background for 11 generations. Animals were housed with a 12:12h light/dark cycle and were given free access to food and water. All experimental procedures were in accordance with the European Communities Council Directive of 24 November 1986 (86/609/EEC) and local French legislation.

\subsection{Genotyping}

PCR primers (5'TGACACACCTCCGTGTGATT3'; 5'GTTCTGCTGCATCTTGGACA3' for APP and 5'AAGA TCGGCTCCACTGAGAA3'; 5'GTGGGTGATATTGTC CA GGG 3' for Tau) were used to amplify the human transgenes (APP695 $5_{\text {swe }}$ and Tau4R0N $\mathrm{N}_{\mathrm{P} 01 \mathrm{~L}}$ ). For the knock-in PS1, PCR primers (5'AGGCAGGAAGATCACGTGTTCAAGTAC3' 5'CACACGCACACTCTGACATGCACAGGC3') were used to amplify mouse genomic PS1 DNA. After an initial 'hot start' at $94^{\circ} \mathrm{C}$ for $10 \mathrm{~min}, 35$ cycles $\left(94^{\circ} \mathrm{C}\right.$ for $30 \mathrm{~s}$, $55^{\circ} \mathrm{C}$ for $30 \mathrm{~s}, 72^{\circ} \mathrm{C}$ for $40 \mathrm{~s}$ ) were run. The expected PCR products amplified only in $3 \times \mathrm{TgAD}$ mice were $674 \mathrm{pb}$ for APP and $312 \mathrm{pb}$ for Tau. For PS1, the expected PCR product amplified both in WT and 3xTgAD mice, was $530 \mathrm{bp}$. After BstEII enzyme digestion, this product is cleaved only when mutated in two 350/180 bp products [20]. Size of PCR products was checked on $1 \%$ agarose gel.

\subsection{Actimetry}

Spontaneous locomotor activity was measured using an actimeter apparatus (Actimeter system, Imetronic, France) composed of two racks of eight single cages of equal measurements $(21 \mathrm{~cm}$ length $\times 11 \mathrm{~cm}$ width $\times 17 \mathrm{~cm}$ height $)$. A metal food dispenser and a water bottle were inserted in the front of each cage allowing the animal free access to food and water. The cages were illuminated 12 hrs per day starting from 8 a.m. Each cage had infrared captors at each side of the box, allowing the recording of the crossings of the animal inside the cage. The equipment was connected to an electronic interface to communicate with a computer for automatic measurement of spontaneous locomotor activity shown by the animals (front activity, back activity and locomotion).

\subsection{Rotarod Performance Test}

Motor coordination and balance were assessed using a rotarod (Bioseb, model LE8200). During a pre-trial, allowing the mice to familiarize with the rotarod, each mouse was placed on the top of the apparatus revolving at a constant speed $(4 \mathrm{rpm})$. Then, the mice were exposed to 3 trials in which the rotation was accelerated from 4 to $40 \mathrm{rpm}$. Latency to fall was measured and averaged for each trial.

\subsection{Immunohistochemistry}

Animals were deeply anaesthetized with pentobarbital and perfused transcardially with cold PBS followed by $4 \%$ paraformaldehyde/PBS. Brains were removed from the skull and placed in the same fixative another 24 hours. Hereafter, brains were embedded in paraffin using standard protocols. Coronal sections $(8 \mu \mathrm{m})$ were cut on a microtome. After deparaffinization, sections were treated with $90 \%$ formic acid during 6 minutes and blocked with 5\% BSA/0.05\% Tween20 during 1 hour. Sections were then incubated at $4{ }^{\circ} \mathrm{C}$ overnight with the primary antibody (FCA18 [21], diluted 1/800 in $2.5 \% \mathrm{BSA} / 0.05 \%$ Tween-20). After washes, sections were incubated with fluorescent AlexaFluor antibodies (Alexa 488-conjugated, Molecular Probes, 1:1000) at RT during 1 hour. Immunofluorescence was visualized using a confocal microscope (Fluoview10, Olympus).

\subsection{Membrane Fraction Preparation}

Dissected hippocampi of 3xTgAD (AD) and nontransgenic (WT) mice were homogenized in hypotonic buffer (5mM HEPES, pH 7.4, 1 mM EDTA, 0.25 M sucrose, protease inhibitor cocktail from Sigma). The homogenate was clarified by centrifugation at $1000 \mathrm{~g}$ for $5 \mathrm{~min}$ at $4^{\circ} \mathrm{C}$, and the supernatant was centrifuged at $100,000 \mathrm{~g}$ for $1 \mathrm{~h}$ at $4{ }^{\circ} \mathrm{C}$. Membrane pellets were then solubilysed in RIPA buffer (Tris 50mM; pH 7.4 containing $\mathrm{NaCl}(150 \mathrm{mM})$, EDTA $(1 \mathrm{mM})$, Triton X100 (1\%), deoxycholate (0.5\%), SDS $(0.1 \%)$ and protease inhibitor cocktail), centrifuged $100,000 \mathrm{xg}$ for $20 \mathrm{~min}$ at $4{ }^{\circ} \mathrm{C}$ and supernatants were recovered as the soluble membrane fractions.

\subsection{SDS/PAGE and Western Blot Analyses}

Soluble membrane fraction ( $50 \mu \mathrm{g}$ of total protein) were dissolved in SDS sample buffer, separated on Tris Tricine gels $16 \%$ (for C83 and C99 detection) or Tris-Glycine gels $10 \%$ (for actin detection), and transferred to nitrocellulose membranes. Target proteins were visualized by enhanced chemiluminescence (Lumilight Roche) with a mouse monoclonal anti-actin (Sigma) or a rabbit polyclonal anti-APPct antibody (kind gift from Paul Fraser, Toronto, Canada).

\subsection{Preparation of Soluble and Insoluble Brain Fractions}

Dissected hippocampi of 3xTgAD (AD) and wild-type (WT) mice were homogenized in RIPA buffer (Tris $50 \mathrm{mM}$; pH 7.4 containing $\mathrm{NaCl}(150 \mathrm{mM})$, EDTA $(1 \mathrm{mM})$, Triton X100 (1\%), deoxycholate $(0.5 \%)$, SDS $(0.1 \%)$ and protease inhibitor cocktail). After lysis with a Dounce homogenizer and brief sonication, proteins were ultracentifuged $\left(100,000 \mathrm{xg}, 1 \mathrm{~h}, 4^{\circ} \mathrm{C}\right)$ and supernatants were recovered as the soluble fractions. Pellets containing insoluble material were mechanically dissociated in formic acid (70\%) and ultracentrifuged $\left(100,000 \times \mathrm{g}, 1 \mathrm{~h}, 4^{\circ} \mathrm{C}\right)$. Supernatants were kept as the insoluble fractions. Before any analysis, these fractions were neutralized to $\mathrm{pH} 7.5$ with Tris- $\mathrm{HCl}(1 \mathrm{M}, \mathrm{pH} 10.8)$ containing betaine $(25 \mathrm{mM})$ (25 times dilution). 


\subsection{Sandwich ELISA Analysis}

Human $A \beta 40$ and human $A \beta 42$ levels were measured in the soluble and insoluble fractions (see above) using sandwich ELISA kits (Biosource (Invitrogen), France). Using these kits, the minimal detectable amounts of human $A \beta 42$ is $<10 \mathrm{pg} / \mathrm{ml}$ and of human $\mathrm{A} \beta 40$ is $<6 \mathrm{pg} / \mathrm{ml}$.

\subsection{Electrophysiological Analysis}

LTP measurements were performed as previously described [22] by E-Phy-Science, Sophia Antipolis, France. Briefly, 3xTgAD (AD) and wild-type (WT) mice were anesthetized with isoflurane and then decapitated. Heads were immediately immersed in ice-cold freshly prepared artificial CSF (aCSF) for at least 2 min before brain extraction. aCSF was composed of the following (in $\mathrm{mM}$ ): $119 \mathrm{NaCl}, 11 \mathrm{~d}$ glucose, $1.3 \mathrm{MgCl} 2.6 \mathrm{H} 2 \mathrm{O}, 1.3 \mathrm{NaH} 2 \mathrm{PO} 4,2.5 \mathrm{KCl}, 2.5$ $\mathrm{CaCl} 2,26 \mathrm{NaHCO} 3$, gassed with $\mathrm{O} 2 / \mathrm{CO} 2(95 / 5 \%)$ at least $20 \mathrm{~min}$ before use and throughout the experiment. Acute slices $(400 \mu \mathrm{m}$ thick) were prepared with a vibratome (VT 1000S; Leica Microsystems, Bannockburn, IL) in ice-cold gassed aCSF. Sections were incubated in aCSF at $34^{\circ} \mathrm{C}$ for $20 \mathrm{~min}$ and then kept at room temperature for at least $1 \mathrm{~h}$ before recording. Recording was performed in a submerged chamber continuously flowed with aCSF at $1.1 \mathrm{ml} / \mathrm{min}$. In order to prevent polysynaptic responses, concentrations of $\mathrm{MgSO} 4$ and $\mathrm{CaCl} 2$ were elevated to $4 \mathrm{mM}$ each for the recording phase. This condition has no obvious effect on the induction and expression mechanism of LTP in subicular pyramidal cells [23]. Stimulations were delivered in CA1 fibers in the alveus and field excitatory postsynaptic potential (f-EPSP) were recorded from the subicular pyramidal neurons in the middle portion of the subiculum that receives synaptic input from the middle subfield of CA1. The stimulation intensity that produced one-third of the maximal response was used for the test pulses, and the LTP-induction protocol consisted of four trains of 100 stimuli at $100 \mathrm{~Hz}$ repeated every $20 \mathrm{~s}$ as previously described [24]. The signal was amplified with an Axopatch 200B amplifier (Molecular Devices, Union City, CA), digitized by a Digidata 1200 interface (Molecular Devices) and sampled at $10 \mathrm{kHz}$ with Clampex 10 (Molecular Devices).

\subsection{Statistical Analysis}

Statistical analyses were performed with PRISM software (Graph-Pad Software, San Diego. CA) by using the Mann-Whitney test for pairwise comparisons.

\section{RESULTS}

\subsection{9-C57BL/6 Hybrid 3xTg-AD Mice Show Circadian Hypoactivity}

Spontaneous activity of young $3 \times \mathrm{Tg}$-AD mice was measured by actimetry allowing the continuous measurement of activity over a period of several days in a non-stressed environment (Fig. 1). At 2 months of age, wild-type and 3xTgAD mice show similar activity (Fig. 1A upper panel and 1B) that appeared to follow a circadian rhythm with higher activity during the dark phase (8p.m-8.a.m) (Fig. 1A upper panel). However, at 4 months of age, $3 \times$ Tg-AD mice showed drastically reduced spontaneous activity, as compared to age- matched wild-type mice, and this hypoactivity still stood at 6 months of age (Fig. 1A,B). In order to rule out the possibility that the decreased activity could be linked to locomotor deficits, we tested the mice in the rotarod performance test. No differences in the latency to fall off the rotarod were observed between the two strains and both strains displayed increasing latencies over the trials, indicating that the reduced activity in the actimetry test was not linked to reduced locomotor abilities but rather to decreased voluntary activity (Fig. 1C).

\subsection{In 3xTgAD Mice, Hypoactivity but not C99 Accumu- lation is Strongly Influenced by the Genetic Background}

In order to determine the influence of genetic background on the apathy-like behavior, we compared the $3 \times \operatorname{TgAD}$ maintained on the original 129-C57BL/6 hybrid background with $3 \times \operatorname{TgAD}$ mice backcrossed for 11 generations to C57BL/6. After selection and checking the presence of the 3 mutations by PCR genotyping (data not shown), we performed actimetry on C57BL/6-3xTgAD mice. Our data indicated that the spontaneous activity of backcrossed C57BL/6 mice was not altered in either 4 or 6 month-old mice as compared to wild-type mice (Fig. 2A,B) clearly indicating a genetic background effect.

In our earlier paper, we used the cleavage-specific antibody FCA18 to establish the early accumulation of C99 in the 129 hybrid $3 \times \operatorname{TgAD}$ mice [19]. We reported that the FCA18 staining was colocalized with enlarged Cathepsin-B positive structures indicating that the first intracellular compartments accumulating C99 correspond to autophagolysosomes [19]. Immunohistochemical analysis on 6 month-old C57BL/6 mice revealed a similar FCA18associated immunoreactivity in term of intensity and localization (Fig. 3A). These findings were supported by biochemical comparative analysis of 4 and 6 month-old mice, showing that C99 also accumulated in C57BL/6 backcrossed mice (Fig. 3B). Moreover, as previously reported for 129C57BL/6 hybrid mice [19], 6 month-old C57BL/6 mice displayed barely detectable soluble and insoluble $A \beta 40$ and A 342 (Fig. 3C).

\subsection{Alterations of Long Term Potentiation (LTP) are Independent of the Genetic Background in 3xTg-AD Mice}

$3 x T g-A D$ mice have been shown to display early alterations of Long Term Potentiation (LTP) occurring before any detectable $A \beta$-and tau-related anatomical lesions [10]. These recordings were performed in the CA1 region of the hippocampus. However, we found that C99 accumulates within the subiculum rather than in the CA1 region (19) and decided to perform LTP recordings in both the CA1 (data not shown) and the subiculum (Fig. 4A). In 1 month-old hybrid mice, no significant differences in LTP were seen between $3 \times T g A D$ and wild-type mice. At 3 months of age, a trend towards a decrease in LTP was found in the subiculum, and a statistically significant reduction was observed in 6 monthold 3xTgAD mice (Fig. 4B). The same electrophysiological patterns were observed in 6 month-old backcrossed mice, indicating that genetic background did not affect hippocampal long-term potentiation in $3 \times \mathrm{Tg}$-AD mice (Fig. 4A,B). 

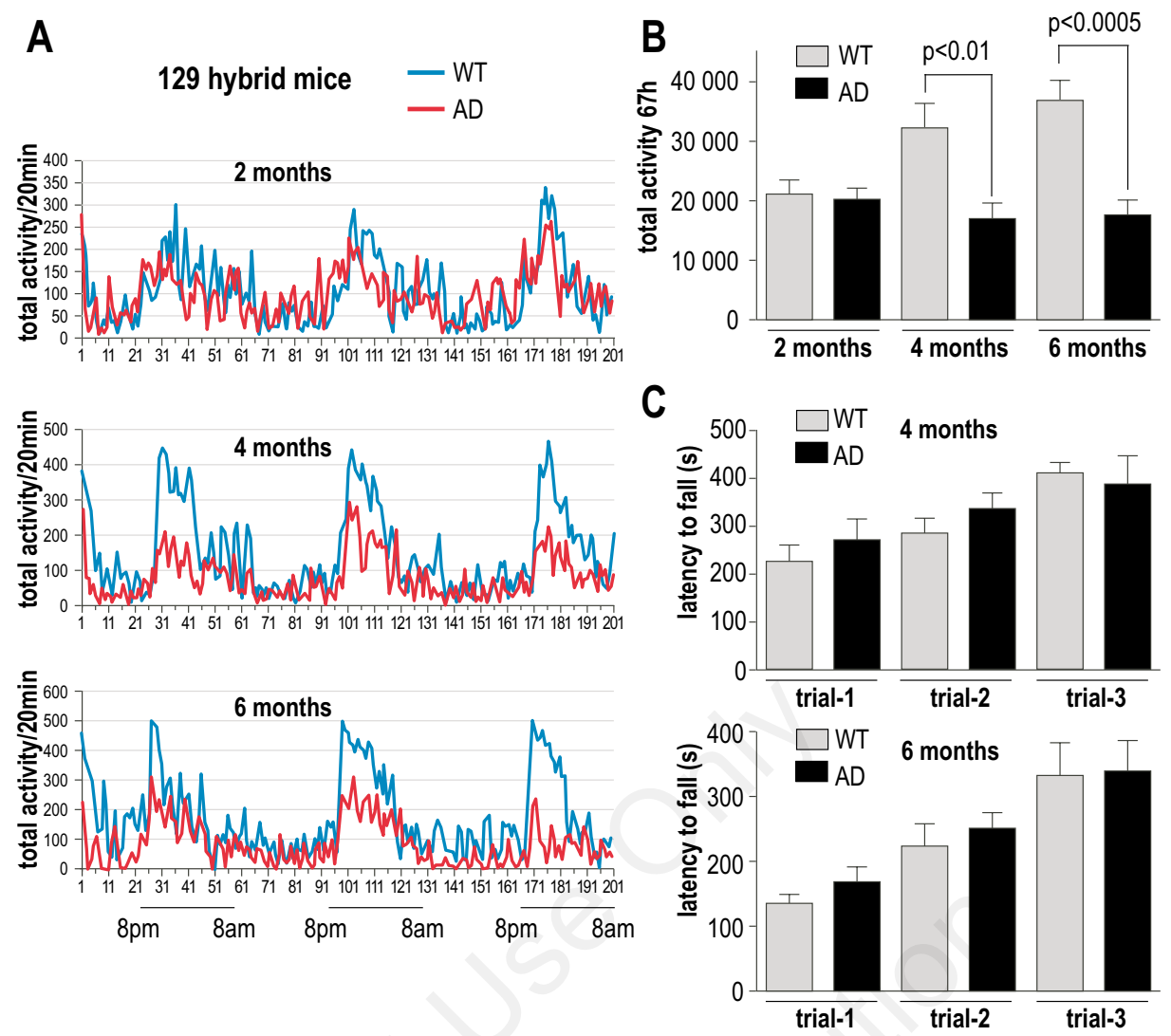

Fig. (1). Age-related decrease of spontaneous activity in 129-C57BL/6 hybrid 3xTgAD mice. (A) Mean of activity waveform recorded each 20 min for 2- 4- and 6-month-old 129-C57BL/6 hybrid wild type (WT) or 3xTgAD (AD) males during a 67h period. (B) Bars represent the means $+/$ - SEM of total activity recorded during $67 \mathrm{~h}$ of 7-9-distinct animals for each age and genotype, p<0.01 (4 month-old mice) or p $<0.0005$ (6 month-old mice) according to the Mann-Whitney test. (C) Rotarod performance test of 4 and 6-month-old 129-C57BL/6 hybrid wild type (WT) or 3xTgAD (AD) males. Bars represent the mean +/- SEM of the latency to fall measured in three independent trials for 8-10 distinct animals for each group.
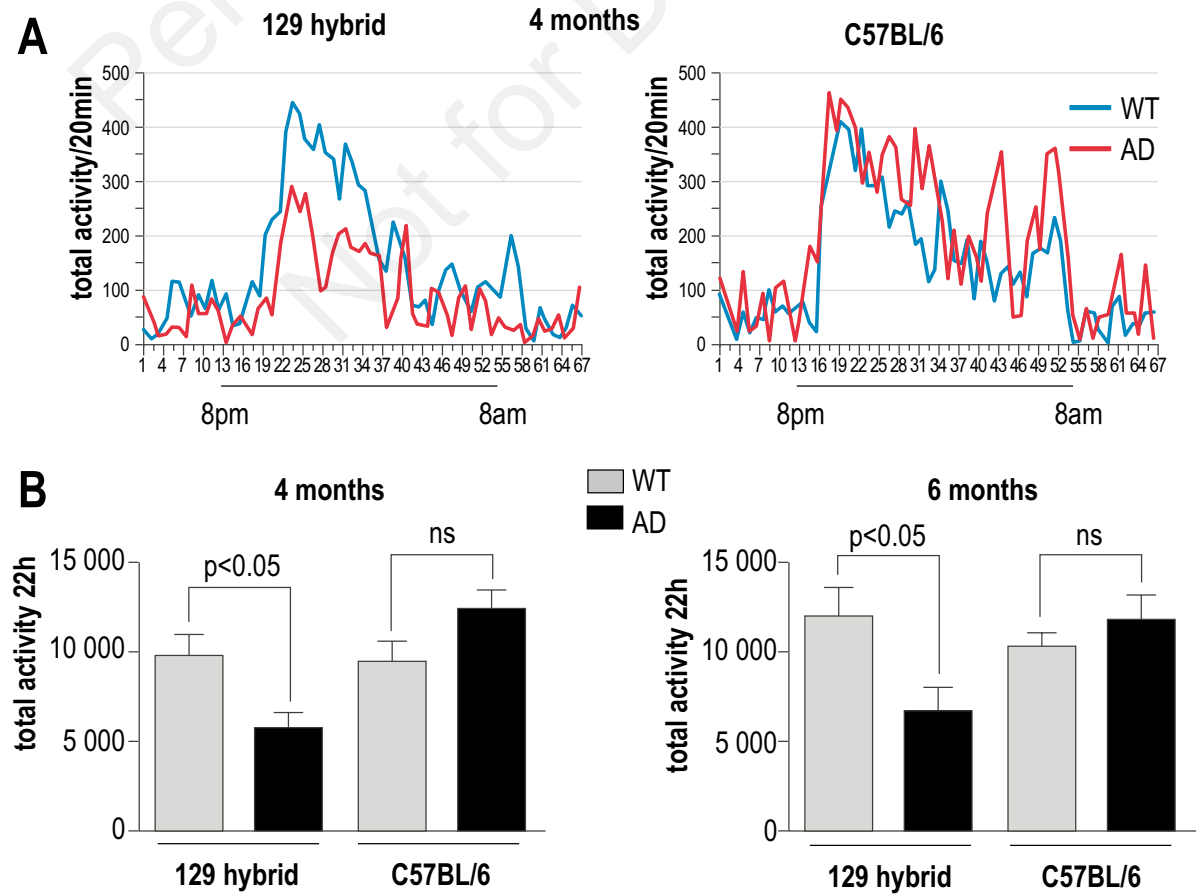

Fig. (2). Influence of inbred strains on spontaneous activity. (A) Mean of activity waveform recorded each 20 min for 4-month-old wild type (WT) or 3xTgAD (AD) males of each inbred strain during a 22h period. (B) Bars represent the means $+/-$ SEM of total activity recorded during $22 \mathrm{~h}$ of 5-8 distinct animals for each group, $\mathrm{p}<0.05$ according to the Mann-Whitney test; ns, not statistically significant. 

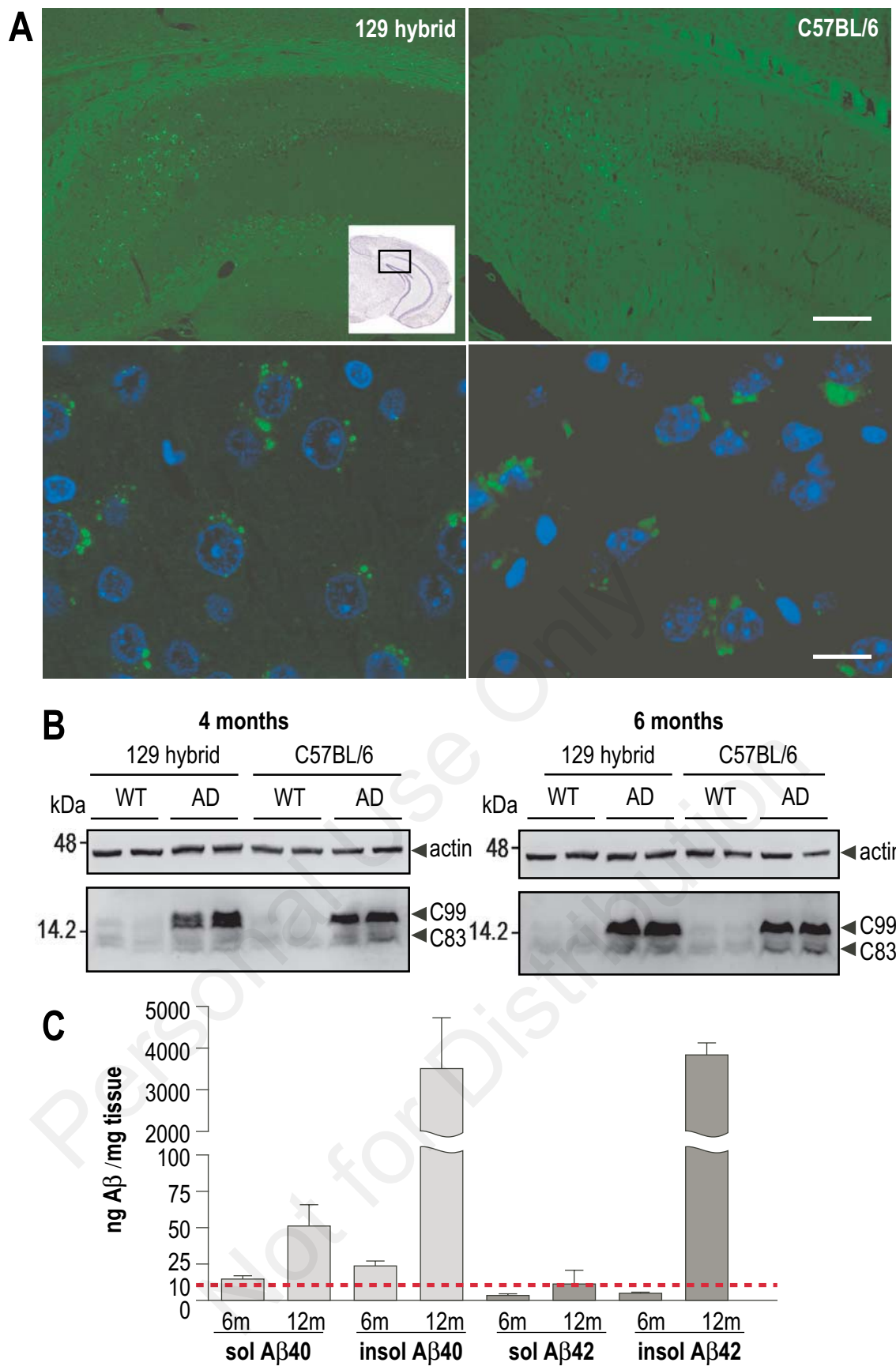

Fig. (3). No influence of inbred strain on C99 accumulation in young mice. (A) Confocal images of FCA18-associated immunohistochemical staining in hippocampus (CA1/subiculum) of 129-C57BL/6 hybrid or C57BL/6 3xTgAD at 6 months of age. Scale bar: $100 \mu \mathrm{m}$ (top) and $10 \mu \mathrm{m}$ (bottom), respectively. (B) Membrane fractions from hippocampi of 4- and 6-month-old 129-C57BL/6 hybrid and C57BL/6 wild type (WT) or 3xTgAD (AD) males were prepared as described in Materials and Method and analyzed for APP-CTF (C99 and C83) expression using APP-Cter antibody. Actin was used as loading control. (C) ELISA analysis of A $\beta 40$ and A $\beta 42$ peptides measured in soluble and insoluble fractions prepared from $\mathrm{C} 57 \mathrm{BL} / 6$ 3xTgAD hippocampi (6- 12-month-old males). Red dotted line corresponds to the human $\mathrm{A} \beta 40$ and $\mathrm{A} \beta 42$ detection threshold.

\section{DISCUSSIONS}

Apathy is mainly defined by a lack of motivation and initiative and affects about $50 \%$ of AD patients. It is the most common and earliest $[15,25]$ neuropsychiatric syndrome before depression in $\mathrm{AD}[13,14]$. Apathy has been shown to be associated with a decrease of motor activity measured by ambulatory actigraphy in $\mathrm{AD}$ patients $[15,25,26]$. In this work we therefore used actimetry to determine whether an apathy-like behavior could be detected in 3xTgAD mice. This technique allows the measurement of spontaneous locomotor activity in a non stressed environment during a period of several days. Indeed, we observed a significantly decreased spontaneous locomotor activity in the 4 and 6 month-old 3xTgAD mice in agreement with earlier published data showing a trend towards a decrease of both diur- 

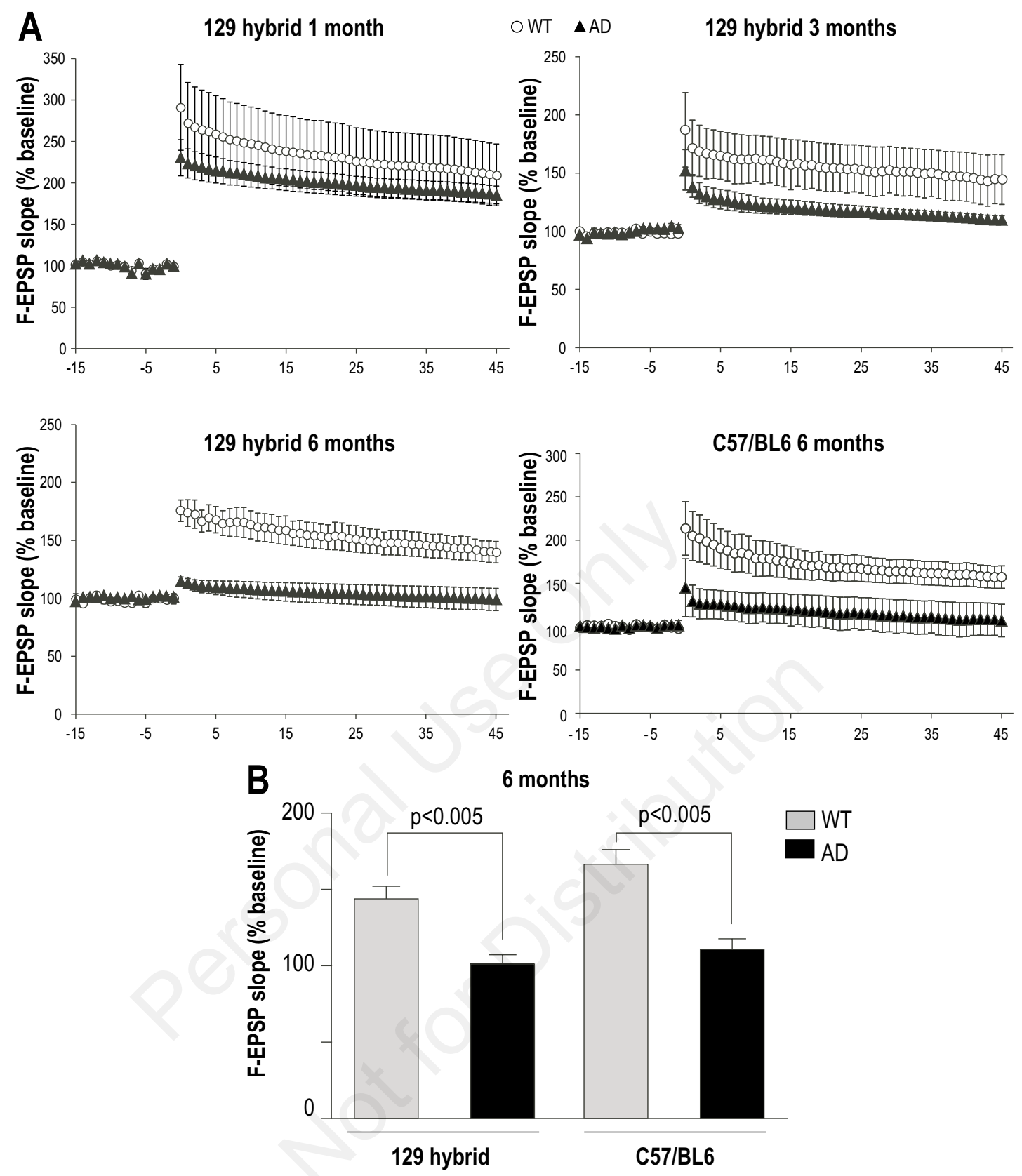

Fig. (4). No influence of inbred strain on LTP impairment. (A) Stimulations were delivered in CA1 fibers and f-EPSPs were recorded from subicular pyramidal neurons. The magnitude of LTP was measured for a minimum of 45 minutes after tetanus and expressed as a percentage of the baseline f-EPSP slope. The mean values observed during the last $15 \mathrm{~min}$ of pre-tetanus recordings were considered to represent the baseline at 100\%. LTP was normal in both wild type (WT) and 3xTgAD (AD) mice at 1 month of age but markedly impaired in 3 and 6 month-old 129-C57BL/6 hybrid or 6 month-old C57BL/6 3xTgAD males. (B) Summary bar graphs depicting levels of potentiation measured between 25 and 45 min after the induction of LTP in 6-month-old 129-C57BL/6 hybrid WT or 3xTgAD mice, as well as in C57BL/6 WT or $3 \times$ TgAD mice, $\mathrm{p}<0.005$ according to the Mann-Whitney test, $\mathrm{n}=6-7$ slices from 3-5 distinct animals for each group.

nal and nocturnal activity [27]. In the rotarod performance test the $3 x \operatorname{TgAD}$ behaved normally, indicating that the reduced activity was linked to diminished voluntary activity rather to reduced locomotor ability. Even though it is tricky to determine a real apathy phenotype in mice, our results in both actimetry and rotarod tests point to an apathy-like phenotype. The reduced motivation in daily and social activities was also supported by our observation doing breeding pairs. We noted a reduced reproductive efficiency in 129-3xTgAD mice compared to wild type. In addition, a recent paper de- scribing impaired nesting behavior of 3xTgAD mice [28] is also in agreement with an apathy-like behavior of 3xTgAD mice.

Our $3 \mathrm{xTgAD}$ mice were maintained on the original hybrid background as it is the case in most laboratories. Some, but few studies have reported data from C57BL/6 backcrossed $3 \times$ TgAD mice $[29,30]$. Since genetic background is known to strongly influence behavior, we compared the two strains and observed that the genetic background strongly 
affected the apathy-like behavior, since both 4 and 6 monthold 3xTgAD C57BL/6 mice did not show hypoactivity, as compared to age-matched wild-type mice.

In our previous paper, we established that these mice display an early appearing intraneuronal accumulation of the $\beta$ secretase-derived $\beta$ APP fragment (C99) occurring in the absence of detectable $A \beta$. We therefore decided to analyze the influence of genetic background on C99 and A $\beta$ accumulation in these young mice. We confirmed the early C99 accumulation and low $A \beta$ levels in the $\mathrm{C} 57 \mathrm{BL} / 6$ mice. We next analyzed the influence of genetic background on hippocampal LTP, which has been found be defective in young $3 x T g A D$ mice [10]. Earlier published studies were all performed by measuring LTP in the CA1 region thought to be particularly affected in AD. Since our work showed that C99 accumulated within the subiculum rather than the CA1 region [19], we recorded LTP in the subiculum and found an early and age-dependent decrease in LTP in 6 month-old $3 \times$ TgAD mice maintained in both 129 hybrid and $\mathrm{C} 57 \mathrm{Bl} / 6$ background. Thus the genetic background did not affect synaptic plasticity alterations.

Taken together, our study confirms that $3 \times \mathrm{TgAD}$ mice can be seen as a relevant model to study AD-related biochemical, anatomical and behavioral alterations. However, our data show that these alterations can be influenced by the genetic background and thus, care should be taken especially when assessing the functional link between these pathological stigmata and cognitive behaviors. The reason why the apathy-like phenotype was lost in mice backcrossed into a pure C57BL6 background remains to be elucidated. However, future studies will establish whether genetic strains dependency apply not only for early phenotypic alterations but also for late cognitive deficits related to learning and memory.

\section{CONFLICT OF INTEREST}

The authors confirm that this article content has no conflict of interest.

\section{ACKNOWLEDGEMENTS}

This work has been developed and supported through the LABEX (excellence laboratory, program investment for the future) DISTALZ (Development of Innovative Strategies for a Transdisciplinary approach to Alzheimer's disease, and by the university hospital Federation (FHU OncoAge). This work was supported by "Conseil Départemantal des Alpes Maritimes". This study was supported by the Innovation Alzheimer association and by the CoBTek research group.

We would like to thank Franck Aguila for artwork.

\section{REFERENCES}

[1] Checler F. Processing of the $\beta$-amyloid precursor protein and its regulation in Alzheimer's disease. J Neurochem 65: 1431-1444 (1995).

[2] Sisodia SS, St George-Hyslop PH. $\gamma$-secretase, Notch, A $\beta$ and Alzheimer's disease: where do the presenilins fit in? Nat Rev 3: 281-290 (2002).

[3] Tanzi RE, Bertram L. twenty years of the Alzheimer's disease amyloid hypothesis: a genetic approach. Cell 120: 545-555 (2005).
[4] Parsi S, Pandamooz S, Heidari S, Naji M, Morfini G, Ahmadiani A, Dargahi L. A novel rat model of Alzheimer's disease based on lentiviral-mediated expression of mutant APP. Neuroscience 284: 99-106 (2015).

[5] Do Carmo S, Cuello AC. Modeling Alzheimer's disease in transgenic rats. Mol Neurodegener 8: 37 (2013).

[6] Cohen RM, Rezai-Zadeh K, Weitz TM, Rentsendorj A, Gate D, Spivak I, et al. A transgenic Alzheimer rat with plaques, tau pathology, behavioral impairment, oligomeric abeta, and frank neuronal loss. J Neurosci 33: 6245-6256 (2013).

[7] Lawlor PA, Bland RJ, Das P, Price RW, Holloway V, Smithson L, et al. Novel rat Alzheimer's disease models based on AAVmediated gene transfer to selectively increase hippocampal Abeta levels. Mol Neurodegener 2: 11 (2007).

[8] Gotz J, Ittner LM. Animal models of Alzheimer's disease and frontotemporal dementia. Nat Rev Neurosci 9: 532-544 (2008).

[9] Puzzo D, Gulisano W, Palmeri A, Arancio O. Rodent models for Alzheimer's disease drug discovery. Expert Opin Drug Discov 307: 26-36 (2015).

[10] Oddo S, Caccamo A, Shepherd JD, Murphy G, Golde TE, Kayed $\mathrm{R}$, et al. Triple-transgenic model of Alzheimer's disease with plaques and tangles: Intracellular $\mathrm{A} \beta$ and synaptic dysfunction. Neuron 39: 409-421 (2003).

[11] LaFerla FM, Oddo S. Alzheimer's disease: Abeta, tau and synaptic dysfunction. Trends Mol Med 11: 170-176 (2005).

[12] Stella F, Radanovic M, Aprahamian I, Canineu PR, de Andrade LP, Forlenza O V. Neurobiological correlates of apathy in Alzheimer's disease and mild cognitive impairment: a critical review. J Alzheimers Dis 39(3): 633-648 (2014).

[13] Robert PH, Berr C, Volteau M, Bertogliati C, Benoit M, et al. Apathy in patients with mild cognitive impairment and the risk of developing dementia of Alzheimer's disease: a one-year follow-up study. Clin Neurol Neurosurg 108: 733-736 (2006).

[14] Chow TW, Binns MA, Cummings JL, Lam I, Black SE, Miller BL, et al. Apathy symptom profile and behavioral associations in frontotemporal dementia vs dementia of Alzheimer type. Arch Neurol 66: 888-893 (2009).

[15] Robert PH, Berr C, Volteau M, Bertogliati-Fileau C, Benoit M, Guerin $\mathrm{O}$, et al. Importance of lack of interest in patients with mild cognitive impairment. Am J Geriatr Psychiatry 16: 770-776 (2008).

[16] David C, Bischoff L, Meudal H, Mothe A, De Mota N, DaNascimento $\mathrm{S}$, et al. Investigation of subsite preferences in aminopeptidase A (EC 3.4.11.7) led to the design of the first highly potent and selective inhibitors of this enzyme. J Med Chem 42: 5197-5211 (1999).

[17] Kuhlmei A, Walther B, Becker T, Muller U, Nikolaus $T$. Actigraphic daytime activity is reduced in patients with cognitive impairment and apathy. Eur Psychiatry 28: $94-97$ (2013).

[18] Martinowich K, Cardinale KM, Schloesser RJ, Hsu M, Greig NH, Manji HK. Acetylcholinesterase inhibition ameliorates deficits in motivational drive. Behav Brain Func 8: 15 (2012).

[19] Lauritzen I, Pardossi-Piquard R, Bauer C, Brigham E, Abraham JD, Ranaldi S, et al. The beta-secretase-derived C-terminal fragment of betaAPP, C99, but not Abeta, is a key contributor to early intraneuronal lesions in triple-transgenic mouse hippocampus. J Neurosci 32: 16243-16255a (2012).

[20] Guo Q, Fu W, Sopher BL, Miller MW, Ware CB, Martin GM, et al. Increased vulnerability of hippocampal neurons to excitotoxic necrosis in presenilin-1mutant knock-in mice. Nat Med 5: 101-106 (1999)

[21] Barelli H, Lebeau A, Vizzavona J, Delaere P, Chevallier N, Drouot $\mathrm{C}$, et al. Characterization of new polyclonal antibodies specific for 40 and 42 amino acid-long amyloid beta peptides: their use to examine the cell biology of presenilins and the immunohistochemistry of sporadic Alzheimer's disease and cerebral amyloid angiopathy cases. Mol Med 3: 695-707 (1997).

[22] Knobloch M, Farinelli M, Konietzko U, Nitsch RM, Mansuy IM. Abeta oligomer-mediated long-term potentiation impairment involves protein phosphatase 1-dependent mechanisms. J Neurosci 27: 7648-7653 (2007).

[23] Roggenhofer E, Fidzinski P, Shor O, Behr J. Reduced threshold for induction of LTP by activation of dopamine D1/D5 receptors at hippocampal CA1-subiculum synapses. PLoS One 8: e62520 (2013). 
[24] Attar A, Ripoli C, Riccardi E, Maiti P, Li Puma DD, Liu T, et al. Protection of primary neurons and mouse brain from Alzheimer's pathology by molecular tweezers. Brain 135: 3735-3748 (2012).

[25] Robert PH, Berr C, Volteau M, Bertogliati C, Benoit M, Mahieux $\mathrm{F}$, et al. Neuropsychological performance in mild cognitive impairment with and without apathy. Demen Geriat Cogn Disord 21: 192-197 (2006).

[26] David R, Mulin E, Friedman L, Le Duff F, Cygankiewicz E, Deschaux O, et al. Decreased daytime motor activity associated with apathy in Alzheimer disease: an actigraphic study. Am J Geriatr Psychiatry 20: 806-814 (2012).

[27] Gimenez-Llort L, Blazquez G, Canete T, Johansson B, Oddo S, Tobena A, et al. Modeling behavioral and neuronal symptoms of Alzheimer's disease in mice: a role for intraneuronal amyloid. Neurosci Biobehav Rev 31: 125-147 (2007).
[28] Torres-Lista V, Gimenez-Llort L. Impairment of nesting behaviour in 3xTg-AD mice. Behav Brain Res 247: 153-157 (2013).

[29] Montgomery SL, Mastrangelo MA, Habib D, Narrow WC, Knowlden SA, Wright $\mathrm{T} \mathrm{W}$, et al. Ablation of TNF-RI/RII expression in Alzheimer's disease mice leads to an unexpected enhancement of pathology: implications for chronic pan-TNF-alpha suppressive therapeutic strategies in the brain. Am J Pathol 179: 2053-2070 (2011).

[30] Liu D, Pitta M, Jiang H, Lee JH, Zhang G, Chen X, et al. Nicotinamide forestalls pathology and cognitive decline in Alzheimer mice: evidence for improved neuronal bioenergetics and autophagy procession. Neurobiol Aging 34: 1564-1580 (2013). 